\title{
DEL PENSAMIENTO CONCEPTUAL AL PENSAMIENTO MÁGICO \\ NOCIONES SOBRE EL ESTATUTO DE LA PRÁCTICA TEÓRICA EN LA CULTURA_RAM
}

\section{FROM CONCEPTUAL THINKING TO MAGICAL THINKING NOTIONS ABOUT THE STATUTE OF THEORETICAL PRACTICE IN THE CULTURE_RAM}

\author{
Ignacio Libretti \\ (Centro de Estudios Visuales NOiMAGEN, Fundación iViCON, Chile) \\ libretti@noimagen.net
}

Recibido el 06 de septiembre de 2017; aceptado el 20 de noviembre de 2017

\begin{abstract}
RESUMEN: el presente artículo aborda los efectos del cambio del régimen escópico dominante sobre el desarrollo de la práctica teórica. Al respecto, problematiza acerca del surgimiento del aparato digital y la cultura_RAM. En esta última, toda información se produce mediante simulacros digitales distribuidos como imágenes-tiempo a lo largo del entramadolink. De esa manera, prima la imaginación codificada a través del programa cibernético por sobre la crítica teórica. Tal modalidad operatoria exige un modelo particular de intelección que rechaza al pensamiento conceptual moderno - propio de las ciencias -, sustituyéndolo por el pensamiento mágico. Aquel, totaliza las apariencias de lo vehiculado en red, rechazando todo giro reflexivo que atente contra la temporalidad acelerada de la realidad virtual. Así, nos encontramos ante un proceso de precarización de la práctica teórica que tiene sus causales en la materialidad misma del aparato digital. Por efecto de esta nueva modalidad informática de la materia, lo imaginario se impone sobre lo conceptual, reforzando las posiciones de la ideología dominante gobernadora de lo visible. La hegemonía de lo imaginario en el seno de la cultura_RAM implica que el pensamiento mágico relegue al pensamiento conceptual, menoscabando el estatuto de la práctica teórica contemporánea.
\end{abstract}

PALABRAS CLAVES: intelección, modalidad, pensamiento, práctica, imaginación.

ABSTRACT: this article is about the effects of the change in the dominant scopic regime on the development of theoretical practice. He talks about the emergence of the digital apparatus 
and the RAM_culture. In this culture, all information is produced through digital simulations distributed as time-images along the link-frame. Here, the coded imagination of the cybernetic program prevails over the critical practice of the scientific theory. Such an operative modality requires a particular model of intellection that rejects modern conceptual thinking - sciences model -, replacing it with magical thinking. This last one totalizes the appearances of the circulating in network, rejecting all reflexive turn that threatens against the accelerated temporality of the virtual reality. In this way, we are facing a process of precariousness of theoretical practice that has its causes in the very materiality of the digital apparatus. As a result of this new cybernetic modality of matter, the imaginary imposes itself on the conceptual, reinforcing the positions of the dominant ideology that rules the visible. The hegemony of the imaginary within the RAM_culture implies that magical thought relegates conceptual thinking, undermining the status of contemporary theoretical practice.

KEYWORDS: intellection, modality, thought, practice, imagination.

\section{INTRODUCCIÓN}

El aparato digital promueve nuevas modalidades para el desarrollo de la práctica teórica. Por su efecto, los contenidos conceptuales y categoriales de cada investigación científica son absorbidos por la lógica RAM. Esta última funciona de forma relacional y fragmentaria, a través del despliegue nodal de imágenes-tiempo distribuidas electrónicamente a lo largo del entramado-link en red; un enjambre virtual que obstruye toda retención conceptual crítica. "Nada de consigna ni preservación: puros operadores relacionales de datos" (Brea, 2010: 83). Aquí, todo contenido es información imaginaria. Por lo tanto, su recepción depende de un modelo particular de intelección: el pensamiento mágico.

El pensamiento mágico consiste en la consecución temática de contenidos de todo tipo - científicos, filosóficos, políticos, estéticos, emocionales, etc. - mediante imágenes. "El significado de las imágenes es mágico" (Flusser, 2001: 11). En ellas, toda potencia cognitiva se subordina a su proyección imaginal. De esa manera, el pensamiento mágico solo es capaz de proveer premisas superficiales. Al pensamiento mágico le acompaña el simulacro de lo imaginado; o sea, la saturación informacional por apariencias. Se trata del complot entre imagen e información. El pensamiento mágico se traduce en el simulacro informacional imaginario, el cual sustantiva las apariencias pensadas volviéndolas totalidades de sentido transparentes y herméticas. 
La conjunción entre aparato digital y pensamiento mágico promovió un nuevo escenario para la práctica teórica occidental. Con la masificación de internet, surgió la cultura_RAM, modalidad de inserción social de la cibernética. "Cultura_RAM significa: que la energía simbólica que moviliza la cultura está empezando a dejar de tener un carácter primordialmente rememorante, recuperador, para derivarse a una dirección productiva, relacional” (Brea, 2007: 13). De esa manera, las prácticas sociales comenzaron a espectralizarse. Siendo la práctica teórica una práctica entre prácticas (Althusser, 2015a: 100 y ss.), sus mecanismos de producción y recepción también mutaron. La lógica ceremonial instaurada por los enciclopedistas de la Ilustración, basada en la teoría del conocimiento y dominante hasta mediados del siglo XX, fue desplazada por la imposición de una praxis cognitiva fragmentaria. Estamos frente al ocaso del pensamiento conceptual.

El pensamiento conceptual consiste en la intelección temática través de abstracciones textuales basadas en códigos racionales de inspiración científica. Es fundamental para la rigurosidad teórica. Del pensamiento conceptual depende la cientificidad de la teoría. Con el surgimiento del aparato digital, correlato de la masificación comercial de la cibernética, la temporalidad dominante se aceleró, menoscabando los requerimientos reflexivos y críticos inherentes al pensamiento conceptual. "Con la aceleración ya no hay el aquí y el allá, sólo la confusión mental de lo cercano y lo lejano, el presente y el futuro, lo real y lo irreal" (Virilio, 1996: 45). Nació así el fantasma de la obsolescencia. De esa manera, se produjo una disfunción entre el sentido originario de la práctica teórica enciclopedista y la sensibilidad epocal. Todo esto, por efecto del aparato digital.

"Un aparato es lo que articula lo sensible y la ley bajo la forma de un llamado a la singularidad y al ser común" (Déotte, 2012: 72). Con el aparato digital, lo imaginario adquirió un lugar privilegiado entre las prácticas sociales. De esa manera, el pensamiento mágico relevó las funciones del pensamiento conceptual, subordinándolo. Las superficies adquirieron un privilegio cognitivo gracias a la economía de la transparencia digital. En ella, no hay más allá posible. Todo es código. La práctica teórica contemporánea está obligada a lidiar con el simulacro informacional imaginario. En él, "lo real se produce a partir de unidades miniaturizadas, de matrices, de bancos de memoria y de modelos de órdenes - de este modo puede reproducirse un número infinito de veces. Ya no tiene porqué ser racional, puesto que ya no se mide en función de instancia ideal o negativa alguna. No es más que algo operativo" (Baudrillard, 2001: 254). Se trata de la hegemonía de las superficies y la totalización de las 
apariencias.

A partir de lo anterior, nos preguntamos por el estatuto de la práctica teórica en la época del aparato digital. Nuestra tesis principal es que la cultura_RAM promueve el tránsito desde el pensamiento conceptual hacia el pensamiento mágico, modificando el estatuto de la práctica teórica a través de la hegemonía imaginal. Para sumergirnos en este problema, nos proponemos indagar tres variables preliminares: 1) la cibernética: nueva modalidad de la materia; 2) cultura_RAM y hegemonía de lo imaginario; 3) el pensamiento mágico contra el pensamiento conceptual.

Esperamos aportar nociones útiles para comprender las modalidades de la práctica teórica en las condiciones presentes.

\section{LA CIBERNÉTICA: NUEVA MODALIDAD DE LA MATERIA}

El desarrollo productivo de posguerra promovió una nueva modalidad de la materia: la información. "Desde el comienzo de la posguerra, a la materia, que hasta entonces era considerada desde el punto de vista de la masa y la energía, se le agrega, para completarla, la noción de información” (Virilio, 1996: 148-149). Se produjo así una torsión epocal en el estatuto de la energía, producido por el amplio desarrollo tecnológico belicista. "Luego de la energía en potencia (potencial) y la energía en acto (cinética), surge la eventualidad de una energía en información (cibernética)" (Virilio, 1996: 149). De esa manera, fueron sentadas las bases para el surgimiento de un nuevo aparato epocal. Lo anterior comenzó con la irrupción de la cibernética.

La cibernética simula lo real a partir de su modulación como realidad virtual codificada. Sin embargo, su vocación no es literaria; no busca crear mundos fantásticos que dialoguen analógicamente con el mundo real. Por el contrario, lo que busca es moldear el efecto de realidad a partir de su codificación. Algo así como el mapa que se apropia del territorio. La realidad es efectiva. Mientras pueda producirse, no podemos hablar de su desaparición. La cibernética informatiza el hacer-mundo necesario para la producción de lo real. Procesa los estímulos electrónicos a través de sus programas, proyectándolos virtualmente. Por su efecto, "la realidad ha pasado a ser la presa de la Realidad Virtual" (Baudrillard, 2008: 21). De esa manera, nos encontramos ante una nueva modalidad de la materia.

Dadas sus particularidades funcionales, la cibernética responde a una temporalidad 
propia. Por esa razón, su inserción social trajo consigo el surgimiento de un nuevo aparato: el aparato digital. Este último consiste en la simulación del aparecer de lo real a través de medios informáticos e imaginarios. En el aparato digital, todo es información e imagen. Una vez que la cibernética pasó de ser monopolio militar a potencia mercantil, sus productos comenzaron a pugnar por la administración del principio de realidad. Eso quiere decir que los dispositivos digitales, moduladores del aparecer propio del hacer-mundo virtual, procuraron signar la experiencia a través de sus códigos; o sea, mediante su lenguaje. "Lo dado de la experiencia es de entrada lenguaje, un lenguaje: es decir, un signo" (Lacan, 2009: 76). Así, el aparato digital se instaló como hacedor de realidad.

La signación de la experiencia por parte de los aparatos epocales es posible por su apropiación de lo imaginario. "Los aparatos deben extraer su material no de lo real sensible, sino del plasma imaginal" (Déotte, 2013: 51). Con él, articulan lo real desde su mismísima emergencia. El hacer-mundo cibernético inauguró una nueva dimensión de la realidad: la virtual. Como vemos, no se trata de lo real y su doble, sino más bien de una redefinición de lo real a partir de la revolución científica de la informática. La categoría de realidad se mantiene. Lo que cambió fue su concepto. La codificación se volvió parte de su definición como tal.

Sin embargo, las transformaciones acarreadas por la cibernética no responden al esquema hilemórfico aristotélico, sino al problema de la materialidad de lo real. Con la realidad virtual, mutaron las modalidades de articulación de las relaciones sociales. No se trata de la incorporación de los contenidos sociales en medios electrónicos neutros, dispuestos a conservarlos tal y como provienen desde el exterior, sino de la transformación de sus mecanismos de producción y recepción por efecto del aparato digital. La cibernética transformó radicalmente las modalidades productivas y receptivas de realidad. En ella, todo está filtrado por códigos y programas que simulan lo real mediante herramientas técnicas internas. Se trata del ocaso del referente.

La materialidad digital vuelve dispensable los horizontes históricos referenciales. Los dispositivos digitales poseen la capacidad programática para simular realidades intemporales. Sus productos responden a la lógica de la saturación por superficie. En ellos, lo aparente se presenta como totalidad transparente, hermética, autosustentable y desechable al parpadeo. Se trata del auge del simulacro, y con él, la consumación de la Ideología de Estado (Althusser, 2015b: 176 y ss.). No hay lugar para horizontes de sentido alternativos al impuesto por la 
ideología dominante, pues los referentes están clausurados. El carácter procesual de la lógica RAM obstruye los anclajes de sentido históricos. Las imágenes digitales son filiales exclusivas del entramado-link. "Lo que con la imagen- tiempo comparece es algo mucho más decisivo e inquietante: en sus escenarios ya no cabe ni la historia - el relato unificado, unidimensional, de un lo mismo - ni la Historia" (Brea, 2010: 74). De esa manera, toda construcción de sentido responde a la unión fragmentaria de elementos heterodoxos vinculados por la invariable del código-matriz.

La saturación por superficie característica del aparato digital, modula la realidad en un doble sentido. Por una parte, informática - administración electrónica de datos -. Por otra, imaginaria - proyección de datos mediante imágenes técnicas -. La cibernética opera como una interfaz que simula realidad a partir de información imaginaria. Se apropia de lo real cercándolo virtualmente. Dicha apropiación de lo real mediante información imaginaria simulada programáticamente implicó el desarrollo de un tipo particular de cultura: la cultura_RAM.

\section{CULTURA_RAM Y HEGEMONÍA DE LO IMAGINARIO}

Con el surgimiento del aparato digital comenzó el cambio paulatino del régimen escópico dominante en Occidente. El régimen escópico "ha de ser entendido como el complejo entramado de enunciados, visualidades, hábitos, prácticas, técnicas, deseos, poderes... que tienen lugar en un estrato histórico determinado" (Hernández-Navarro, 2016: 20). Por tanto, regula las modalidades de asimilación del aparecer. Al régimen escópico corresponden los trazos del campo de visualidad preliminar para cada comunidad humana. Nos encontramos ante la relación privilegiada entre régimen escópico e imágenes dominantes.

Dado que “vivimos con imágenes y entendemos el mundo en imágenes” (Belting, 2007: 14), ellas son fundamentales para la producción del principio de realidad. El efecto de realidad es siempre imaginario. El régimen escópico impregna de su materialidad a cada comunidad humana a través del nexo con sus imágenes. Hasta la primera mitad del siglo XX, el régimen escópico dominante fue el inconsciente óptico. En él, un punto ciego y técnico administraba la aparición de los contenidos objetivados. Puede definirse como "algo en lo que vemos que no sabemos que vemos, o algo que conocemos en lo que vemos que no sabemos $<<$ suficientemente $>>$ que conocemos" (Brea, 2007: 179). O sea, la precesión de una certeza efectiva sobre el fundamento rector de todo fenómeno, visible a través de los dispositivos 
técnicos disponibles. El inconsciente óptico encontró en la cámara fotográfica su dispositivo mejor modulado. "La naturaleza que habla a la cámara es distinta de la que habla a los ojos; distinta sobre todo porque un espacio elaborado inconscientemente aparece en lugar de un espacio que el hombre ha elaborado con consciencia" (Benjamin, 1989: 67). Por tanto, en el inconsciente óptico siempre hay un punto de acolchamiento que sostiene la proyección objetivada.

Con la cibernética, la situación cambió. La capacidad de simular realidades a través de programas que solo responden al procesamiento de impulsos electrónicos internos inauguró una nueva dimensión problemática. Los residuos referenciales aún necesarios para los mecanismos propios del inconsciente óptico se volvieron totalmente innecesarios para el aparato digital. Sus dispositivos solo necesitan de códigos y algoritmos para simular realidades, apropiándose de lo real mediante su saturación superficial. La virtualidad se posicionó como un nuevo horizonte, promoviendo el dominio de un nuevo régimen escópico. Al inconsciente óptico le sucedió la $e$-image, y con ella el régimen de las 1.000 pantallas (Brea, 2007: 196).

La particularidad de este nuevo régimen escópico de las 1.000 pantallas es su materialidad: imágenes-tiempo. Mientras el inconsciente óptico aún requería de referentes para la elaboración de sus productos técnicos, la e-image solo necesita de impulsos electrónicos para animar los mecanismos del enjambre matricial del entramado-link. De esa manera, sus productos circulan como información imaginaria autorreferencial. Simulan contenidos procesuales al parpadeo. "Inmersión, inmanencia, inmediatez: he aquí las características de lo Virtual" (Baudrillard, 2008: 26). La realidad virtual desplazó la intelección conceptual hacia una coherente con el flujo informacional mediante imágenes: el pensamiento mágico.

La temporalidad particular del aparato digital obstruye la irrupción de la dimensión histórica. De esa manera, la ética fragmentaria de las 1.000 pantallas no solamente se apropia del presente, sino también del pasado. El funcionamiento procesual del entramado-link promueve nuevas modalidades de aculturación mediante simulacros identitarios. Los fragmentos fantasmales simulados digitalmente asaltan lo real, apropiándoselo. De esa manera, nació la cultura_RAM; producto social de la hegemonía de las imágenes-tiempo en la gestión de subjetividad. Al respecto, Brea comentó (Brea, 2007: 193):

Las nuevas comunidades ya no se constituyen tanto en la adhesión fidelizada a una narrativa específica, que hacen objeto de su fe compartida, sino sobre todo en la relación 
puntual y dinámica con una constelación de imágenes en circulación con las que se produce una relación de identificación y reconocimiento que poco a poco las va sedimentando como memoria compartida, imaginario colectivo.

Nos encontramos ante el imperialismo de las imágenes-tiempo. En las 1.000 pantallas, ellas monopolizan las construcciones de sentido, saturándolas de su transparencia. Mientras el inconsciente óptico se basaba en un punto ciego, las 1.000 pantallas se basan en la transparencia de las superficies. No existiendo ocultación alguna, desaparece el modelo mental analítico. La imagen digital se representa a sí misma como el todo y la parte. "La transparencia ha devorado el mundo hasta hacerlo opaco a sus habitantes. La opacidad no está ya en <<las cosas〉> sino en nuestra capacidad de ver, o en los límites que surgen en nuestra conciencia saturada por el modo constante con el que las cosas invaden nuestra visión” (Comeron, 2007: 72). El régimen escópico de las 1.000 pantallas promueve el desarrollo del pensamiento mágico.

La pragmática digital usurpa la realidad despojándola de sus matices. Proyecta sobre ella sus algoritmos programáticos, imponiéndolos. El código se vuelve la invariable de lo real. De esa manera, las imágenes-tiempo saturan la información mediante su estetización. El efectismo mágico ya incipiente desde el surgimiento de la televisión, encontró su auge en la eimage. "En lo sucesivo, la información se impone a la realidad del acontecimiento" (Virilio, 1996: 156), transformándose en información imaginaria. No requiere rigurosidad alguna. Solo busca conmover, consumando fines políticos y publicitarios acuciosamente elaborados. Se trata de la economía de la transparencia imaginaria. "Tras el barroco de las imágenes se esconde la eminencia gris de la política" (Baudrillard, 2001: 256). La cultura_RAM es la fase superior del simulacro moderno inaugurado por las imágenes técnicas a principios del siglo XX.

La totalización de las apariencias vuelve superflua la reflexión arqueológica del conocimiento. La transparencia simulada digitalmente obstruye la pregunta por las condiciones de lo proyectado. El efecto precede a la reflexión. En este horizonte, el pensamiento conceptual resulta superado por el pensamiento mágico. Este último es mucho más rápido, pues apela a la inmediatez ideológica dominante. Siendo la realidad efectiva, ella puede simularse fácilmente mediante imágenes montadas digitalmente, obviando cualquier proceso ajeno al entramadolink. Se trata de una nueva religiosidad electrónica de la transparencia simulada, alimentada por las variables de la ideología dominante. Salvo internet, todo es ilusión. 


\section{EL PENSAMIENTO MÁGICO CONTRA EL PENSAMIENTO CONCEPTUAL}

La cultura_RAM se piensa a sí misma a través de imágenes. Eso quiere decir que sus modalidades de reconocimiento no responden a relatos históricos, sino a fragmentos imaginales dispersos en la red. La hegemonía de la imagen es un efecto propio del predominio de la lógica RAM. Su materialidad le exige operar a través de la totalización de las superficies. Sin embargo, ella no inauguró la relación entre las comunidades humanas y sus imágenes. Dicha relación responde a la institución del signo. Con el dominio burgués a cuestas, las comunidades humanas se transformaron en formaciones sociales signadas por diversas modalidades de intercambio de equivalentes. Una de ellas fue la del intercambio simbólico. "El discurso simbólico es un idioma" (Baudrillard, 1976: 43). Está mediatizado por las imágenes-de intercambiadas. Articula lo real volviéndolo imaginable. En ese sentido, las imágenes poseen un carácter atributivo, del cual Flusser señaló lo siguiente (Flusser, 1996: 13):

Las imágenes son intermediarios entre el mundo y los hombres. El hombre ex-siste, es decir, no accede al mundo de forma inmediata, sino a través de las imágenes, que le permiten imaginarlo. Pero en cuando se lo representan, se interponen entre el mundo y el hombre. Sirven como mapas y se convierten en pantallas: en lugar de representar el mundo, lo desfiguran, hasta que el hombre finalmente empieza a vivir en función de las imágenes que crea.

Por su función de tal, las imágenes poseen un potencial usurpador de la realidad. Ellas suplantan lo imaginado a partir de la totalización de su apariencia. Esto se mantiene en la medida que los hombres no son capaces de traspasarlas; o sea, de reflexionarlas conceptualmente. Dicho potencial usurpador corresponde a lo que Spinoza llamó el Primer Género de Conocimiento (Spinoza, 2011: 181-182). En él, la imaginación atribuye características a lo imaginado siguiendo las nociones ideológicas dominantes. Como podemos ver, se trata de un conocimiento positivo. No responde a la dupla verdad/error, sino a la información mediante deformación imaginaria. Irrumpe así la cuestión de la ideología. Althusser explicó la relación privilegiada entre imaginación e ideología en los siguientes términos (Althusser, 2015b: 222):

[...] en su deformación necesariamente imaginaria, toda ideología representa no las relaciones de producción existentes (y las demás relaciones que de estas derivan), sino ante todo la relación (imaginaria) de los individuos con las relaciones de producción y 
con las relaciones que de estas derivan. En la ideología se representa, por tanto, no el sistema de las relaciones reales que gobiernan la existencia de los individuos, sino la relación imaginaria de estos individuos con las relaciones reales en las cuales viven.

Para Spinoza, la ruptura con el Primer Género de Conocimiento y, por tanto, con la ideología, solamente es posible a través de un salto hacia el Segundo Género de Conocimiento (Spinoza, 2011: 182). Este último corresponde al ámbito de la ciencia. Él provee las nociones necesarias para hacernos una idea verdadera del fenómeno inicialmente imaginado mediante recursos ideológicos. Aquí, hace su aparición el pensamiento conceptual a través de la escritura. "Los textos no significan el mundo, sino que significan las imágenes que rompen" (Flusser, 2001: 14). Gracias a ellos, podemos concebir la realidad más allá de la usurpación imaginaria.

Con la irrupción del aparato digital, el salto intelectual desde el Primer Género de Conocimiento hacia el Segundo Género de Conocimiento encuentra grandes dificultades. El carácter totalizador de la experiencia digital obstruye la reflexión acerca de las condiciones de producción del simulacro informacional. De esa manera, el flujo de las imágenes en red trae consigo la precarización del ejercicio conceptual y, con él, el menoscabo de la práctica teórica. Sin ir más lejos, la propia información vehiculada a través del entramado-link se supedita a las imágenes que la movilizan. Por su carácter productivo, el simulacro implica de por sí la manipulación de lo simulado. Lo más problemático del asunto no es solo la manipulación temática, sino el modelo de intelección que acarrea. La información imaginaria "no solamente puede ser, como se ha dicho, manipulada, sino que la imagen (que no es más que una entre millares de otras) ejerce una influencia y posee un poder que excede en mucho la información objetivada de que es portadora" (Auge, 2000: 38). La imagen es mágica. He allí su encanto y su poder.

La hegemonía de la imagen, principio angular de la cultura_RAM, acarrea la siguiente paradoja: a mayor número de información flotante en red, menor capacidad receptiva para la discriminación crítica de sus contenidos y funciones políticas motrices. La total transparencia que promueve el aparato digital está en proporción directa con la mengua en las capacidades sociales de intelección, inscritas en la materialidad misma del nuevo régimen escópico, y en proporción inversa a la rigurosidad de la información vehiculada. Las 1.000 pantallas proveen innumerable cantidad de datos. Sin embargo, la inducción imaginal matricial y el 
funcionamiento nodal de su interfaz saturan el acceso del usuario, impidiendo la digestión conceptual de los estímulos electrónicos. Ante la anulación relacional de la intelección promovida por el entramado-link, la recepción digital se vuelve una ceremonia religiosa oficiada por la e-image de turno. "El modelo de acceso matricial permite la puesta en encuentro de cualquier clúster o escena con cualquier otra - sin la restricción de la economía de lectura longitudinal, secuenciada y sucesiva, que pesa en los procedimientos del libro o film -." (Brea, 2010: 85). La aleatoriedad del proceso de navegación se vuelve una norma receptiva. En ese horizonte, el dominio del pensamiento mágico resulta patente.

En la cultura_RAM, el pensamiento mágico domina al pensamiento conceptual, supeditándolo. La práctica teórica - propia del Segundo Género de Conocimiento - se ve permanentemente asediada por la deformación imaginaria - característica del Primer Género de Conocimiento -. Así, la producción de conocimientos está obligada a lidiar no solo con las amenazas ideológicas propias del oficio, sino además con un modelo de recepción epocal que rechaza la crítica y las evidencias, abrazando las intuiciones devenidas del plasma imaginal. La precarización resulta evidente. Aunque la digitalización de contenidos promueve tanto el acceso como la distribución democratizada de contenidos, el régimen escópico de las 1.000 pantallas menoscaba las capacidades receptivas de las masas, fomentando su intelección mediante imágenes saturadas. Dichas imágenes corresponden a lo aparente de cada fenómeno; su transparencia anticonceptual. En las 1000 pantallas, la proyección imaginal se convierte en la única construcción de sentido válida. La riqueza de matices desaparece. La transparencia se traduce, a su vez, en la anulación de todo horizonte sintomático.

Contra la cientificidad necesaria para la rigurosidad de la teoría, el pensamiento mágico impone el culto a la superficie. Y no lo hace mediante un gesto de alienación, sino de constitución de los sujetos; o sea, sin precesión alguna. No existe un ante-humano puro, desnudo de todo influjo productivo. La subjetividad digital responde a la asimilación de un modelo de recepción mental que proviene de la interfaz visual del entramado-link. "El espacio mental no está supeditado, pues, únicamente al lenguaje, sino que también las disposiciones visuales son susceptibles de fundamentarlo" (Catalá, 2010: 92). El carácter atributivo de la imagen resulta patente. Claramente, no estamos ante un fenómeno que se restrinja a las variables de verdadero y falso.

En el aparato digital, toda producción textual se transforma en la imagen electrónica de 
un escrito. Así, el pensamiento mágico subordina al conceptual, aun cuando este último se despliega como tal. Se trata de la absorción de un pensamiento por otro desde sus mismísimas prácticas regulares. En red, la práctica teórica coexiste con las variables paralelas que alberga el entramado- link. El enjambre digital vehicula fragmentos flotantes de diversas temáticas, obstruyendo la reflexividad crítica. La matriz de internet está fabricada para la navegación ininterrumpida entre nodos; no para la permanencia estática en uno de ellos. De esa manera, el pensamiento conceptual debe lidiar con las dificultades de un régimen escópico que lo rehúye por principio.

Todo parece indicar que la práctica teórica deberá transformar sus formas de producción, recepción e inserción social, para combatir las nuevas modalidades de malversación ideológica inducidas por el pensamiento mágico. En ese punto irrumpe la relación entre ciencias y política. Sin embargo, dado que tal problemática excede los propósitos de este artículo, dejaremos en suspenso su desarrollo. Por ahora nos conformamos con aportar algunas nociones básicas sobre el tránsito epocal desde el pensamiento conceptual al pensamiento mágico.

\section{ALGUNAS CONCLUSIONES}

De lo visto anteriormente podemos concluir lo siguiente: a) la cibernética implicó el surgimiento de una nueva modalidad operatoria de la materia (la informática) y no su desaparición; b) la cibernética se transformó en un aparato epocal una vez asimilado socialmente gracias al capitalismo contemporáneo; c) el aparato epocal al cual corresponde la cibernética es el aparato digital; d) la asimilación social del aparato digital se realizó a través de la imposición de su temporalidad propia en el seno de las formaciones sociales occidentales; e) la temporalidad del aparato digital promovió un cambio en el régimen escópico, y con él, el nacimiento de la cultura_RAM; f) la cultura_RAM fue el producto principal del cambio en el régimen escópico dominante; g) el régimen escópico de las 1.000 pantallas vela por el desarrollo de lo imaginario en desmedro de lo conceptual; h) la hegemonía de lo imaginario en la cultura_RAM mina las bases materiales modernas del pensamiento conceptual; i) la dominancia del pensamiento mágico implica un menoscabo de la práctica teórica; j) en la cultura_RAM, la práctica teórica es desplazada por el simulacro digital; k) el aparato digital va en detrimento de la práctica teórica; 1) la hegemonía del pensamiento mágico atenta contra las 
modalidades particulares del pensamiento conceptual, precarizando la práctica teórica, y subordinándola al imperialismo de las imágenes.

\section{REFERENCIAS BIBLIOGRÁFICAS}

ALTHUSSER, Louis (2015a). Iniciación a la Filosofía para los No Filósofos. Editorial Paidós SAICF: Buenos Aires.

- (2015b). "La Reproducción de las Relaciones de Producción”. En Althusser, Louis. Sobre la Reproducción. Ediciones Akal, S. A., Madrid, pp. 31-245.

AUGE, Marc. Los <<No Lugares〉>. Espacios del Anonimato. Una Antropología de la Sobremodernidad. Editorial Gedisa, S.A.: Barcelona.

BAUDRILLARD, Jean (1976). La Génesis Ideológica de las Necesidades. Editorial Anagrama: Barcelona.

- (2001). “La Precesión de los Simulacros”. En Brian Walles (ed). Arte Después de la Modernidad. Nuevos Planteamientos en Torno a la Representación. Ediciones Akal, S.A, Madrid, pp. 253-281.

- (2008). El Pacto de Lucidez o la Inteligencia del Mal. Amorrortu: Buenos Aires.

BENJAMIN, Walter (1989). "Pequeña Historia de la Fotografía". En Benjamin, Walter.

Discursos Interrumpidos I. Filosofía del Arte y de la Historia. Taurus S.A., Buenos Aires, pp. 61-83.

BELTING, Hans (2007). Antropología de la Imagen. Katz Editores: Buenos Aires.

BREA, José Luís (2007). Cultura_RAM. Mutaciones de la Cultura en la Era de su

Distribución Electrónica. Gedisa S.A.: Barcelona.

- (2010). Las Tres Eras de la Imagen. Imagen-Materia, Film, E-Image. Ediciones

Akal, S.A.: Madrid.

COMERON, Octavio (2007). Arte y Postfordismo. Notas desde la Fábrica Transparente.

Trama Editorial y Fundación Arte y Derecho: Madrid.

CATALÁ, Josep M. (2010). La Imagen Interfaz. Representación Audiovisual en la Era de la Complejidad. Servicio Editorial de la Universidad del País Vasco: Bilbao.

DÉOTTE, Jean-Louis (2012). ¿Qué es un Aparato Estético? Benjamin, Lyotard, Rancière.

Ediciones/ Metales Pesados: Santiago de Chile.

- (2013). La Época de los Aparatos. Adriana Hidalgo Editora S.A.: Buenos Aires.

FLUSSER, Vilém (2001). Una Filosofía de la Fotografía. Editorial Síntesis S.A.: Madrid.

HERNÁNDEZ-NAVARRO, Miguel (2016). "El Archivo Escotómico de la Modernidad", 
Revista NOiMAGEN, número 1, Santiago de Chile, pp. 1-59.

LACAN, Jacques (2009). "Más Allá del $<<$ Principio de Realidad>>”. En Lacan, Jacques.

Escritos 1. Siglo XXI Editores, S.A., México D.F., pp. 81-89.

SPINOZA, Baruch (2011). Ética Demostrada Según el Orden Geométrico. Alianza Editorial, S.A.: Madrid.

VIRILIO, Paul (1996). El Arte del Motor. Aceleración y Realidad Virtual. Ediciones

Manantial: Buenos Aires. 